\title{
Vale a pena avaliar periódicos científicos?
}

$\mathrm{E}$ stima-se que cerca de 1.000 .000 de revistas científicas sejam publicadas anualmente no mundo, totalizando algo entre 6 e 7 mil artigos científicos sendo escritos diariamente! ${ }^{1}$ Tal profusão de títulos, eventualmente testemunho de um espetacular vigor da produção de conhecimento, nem sempre é acompanhada da obediência aos padrões necessários de qualidade para uma publicação científica, desencadeando, em âmbito internacional, uma onda de críticas ao empreendimento editorial.

De acordo com Krzyanowski e Ferreira (1998), tais críticas à qualidade das revistas dizem respeito, entre outros pontos, à irregularidade na publicação e distribuição, ausência de normalização (da revista e/ou dos artigos), problemas relativos ao corpo editorial e sistema de arbitragem. A isso, adicionam-se, em casos como o brasileiro, o baixo impacto do material produzido devido à língua, eventuais problemas de originalidadee novidade do material-enfim, problemas jámuito conhecidos dos que estudama "cartografia" científica².

O quadro assim delineado não deixa muita margem para questionamentos acerca da necessidade de avaliação dos periódicos. Todavia, avaliar significa estabelecer parâmetros de excelência, tarefa de difícil execução quando o que está em jogo, em última análise, é a produção de conhecimento.

Não é lugar nem oportunidade para discutir essa questão, de mais a mais, já objeto de intensas discussões nos chamados campos da Sociologia e Filosofia da Ciência. A questão a ser posta, aqui, é: será possível definir (e se sim, quais seriam) os parâmetros indispensáveis para que uma publicação científica seja digna de crédito?

Com esta questão, a Comissão Editorial CAPES/ ANPEPP iniciou seus trabalhos no segundo semestre de 1998, tendo por responsabilidade avaliar os periódicos científicos brasileiros referidos pelos participantes dos programas de pós-graduação da área da Psicologia ${ }^{3}$.

A avaliação provocou reações as mais diversas, da indignação pelos critérios definidos adhoc na opinião dos críticos, a elogios pelo esforço julgado sério e necessário por parte de outros. Uma “avaliação da avaliação", solicitada pela ANPEPP a especialistas, apontou suas virtudes e deficiências mas, em termos gerais, pode-se dizer que o processo foi aprovado (Hutz, 2000).

Passados pouco menos de três anos e duas versões da avaliação, qual o quadro que temos hoje?

É impossível deixar de assinalar, enfaticamente, a melhoria da qualidade das publicações da área, seja aquila- tado pelas alterações na classificação entre as duas avaliações (25 revistas melhoraram seustatus; apenas cinco pioraram), seja pela avaliação informal de editores e bibliotecários, seja pelo simples manuseio do material produzido no período.

Ao lado disso, foi criada uma referência para que os editores possam se pautar na criação ou na reformulação de seus veículos. Dentre essas referências, um ganho que parece inquestionável é a busca pela cobertura desses periódicos pelas bases de dados internacionais. Serviços como o PsycINFO (American Psychological Association), LILACS (Centro Latino-Americano e do Caribe de Informação em Ciências da Saúde), entre diversos outros, passaram a indexar periódicos brasileiros da área. No serviço SciELO (Scientific Electronic Library Online), talvez a mais importante iniciativa de produção de metodologia para publicação eletrônica, o número de solicitações e de efetiva aceitação das revistas da área é outro testemunho do impacto da avaliação CAPES/ANPEPP.

O reconhecimento por parte da comunidade acadêmica é demonstrado, como não poderia deixar de ser, pela incorporação da classificação no sistema Qualis da CAPES, base para a avaliação da produção bibliográfica dos programas de pós-graduação no Brasil, mas também pela adoção por parte de outras agências de fomento (como é o caso do $\mathrm{CNPq}$ ), da classificação como um termômetro da qualidade da produção dos pesquisadores.

Evidentemente, isto teve uma repercussão na comunidade, fazendo com que os periódicos bem avaliados fossem privilegiados pela escolha por parte dos pesquisadores ao submeterem sua produção.

Da mesma forma, criou-se a expectativa de que as revistas que ainda não atingiram determinados patamares de qualidade, procurem adequar suas publicações para que possam receber a contribuição dos pesquisadores. Uma máxima que sempre norteou o trabalho da comissão, convém ressaltar, é que a avaliação não é "um jogo de soma zero", ou seja, a expectativa é de que todas as revistas possam atingir tais padrões de excelência.

Isto posto, a questão inescapável é: mas, realmente, as revistas melhor qualificadas atingiram padrões de excelência?

Esta questão nos remete, no momento em que se prepara a terceira versão da avaliação, a voltar nossa atenção para o procedimento até aqui adotado pela comissão.

Dentre as questões a serem enfrentadas, algumas já estão em discussão. Menandro (2001) destaca o ajuste de cri- 
térios para definir o nível de qualidade dos periódicos (sem prejuízo dos progressos realizados), a revisão de critérios para definir a circulação, definição de padrão mínimo de informações e exigências sobre política e procedimentos de tramitação, ampliação do leque de periódicos avaliados (internacionais e de áreas conexas) e definição sobre periódicos disponibilizados eletronicamente.

Existe uma questão, sempre presente e de difícil equacionamento, que é uma avaliação mais direta da qualidade do material publicado, sem desautorizar o sistema de arbitragem dos periódicos. Este problema, apontado nas avaliações feitas pela comunidade acadêmica, coloca-se como um grande desafio nesse processo.

De qualquer forma, o balanço desses três anos de avaliação parece altamente positivo: houve uma mudança qualitativa no quadro editorial da área da Psicologia.

É fundamental que se diga (advogando em causa própria...): tal processo foi desencadeado pela ANPEPP em associação com a CAPES, mas foi conduzido graças ao esforço dos editores, em meio a condições altamente desfavoráveis, na contra-corrente da tendência de desestímulo, no Brasil, a empreendimentos culturais como esses ${ }^{4}$...

Neste fascículo, com o qual encerramos o volume 6, contamos com onze artigos, seis deles na seção regular e cinco no Dossiê Trabalho Infanto-Juvenil, organizado pela editora convidada e membro da Comissão Editorial, RosangelaFrancischini.

Na seção de artigos, Valdiney Gouveia e colaboradores apresentam um estudo sobre a tipologia de Schwartz conduzida com estudantes universitários na Espanha; Estela Cabral e Sandra Sawaya estudam a prática dos psicólogos em serviços de saúde com relação às queixas escolares; Alvaro Tamayo e colaboradores abordam a relação entre atividade física e autoconceito; Maria da Graça Dias e colaboradoras discutem o desenvolvimento da lógica mental predicativa entre crianças; Livia Borges e Antônio Alves Filho enfocam a motivação e o significado do trabalho em profissionais da área da saúde e bancários em Natal (RN) e Daniela Levandowski apresenta uma breve revisão da literatura internacional acerca da paternidade na adolescência.

O dossiê que apresentamos nesta edição aborda um tema que é extrema e dolorosamente atual. De fato, o trabalho infanto-juvenil, longe de ser apenas um efeito colateral, sempre fez parte do núcleo das contradições da sociedade capitalista, é um fenômeno presente não somente nas nações do "terceiro mundo", mas também naquelas mais ricas e industrializadas. Conforme a apresentação detalhada da editora convidada, o Dossiê é composto por artigos que, partindo de olhares diversos, têm em comum a crença na investigação científica para dar respostas às demandas como essa que nos são colocadas no cotidiano, nos diferentes contextos históricos.

A qualidade e a procedência dos trabalhos - de grupos de pesquisadores de diversas partes do país: Brasília, Rio de Janeiro, São Paulo, Rio Grande do Sul e Rio Grande do Norte-, atestam a sintonia da comunidade científica com as questões contemporâneas, contradizendo um refrão que é (irresponsavelmente) repetido pela mídia e até mesmo pelos acadêmicos, acerca do insulamento da instituição universitária.

Finalmente, um agradecimento muito especial aos consultores relacionados na sequiência, que participaram da avaliação dos manuscritos no período 08/2000 a 07/2001, pela inestimável colaboração para a manutenção da qualidade editorial de Estudos de Psicologia.

Oswaldo H. Yamamoto

Editor

\section{Referências}

Gibbs, W. W. (1995). Lost science in the Third World. Scientific American, August, 273, 76-83.

Hutz, C. S. (2000). Avaliação do processo de avaliação das revistas científicas em Psicologia. Estudos de Psicologia, 5, 471-481.

Krzyanowski, R. F., \& Ferreira, M. C. G. (1998). Avaliação de periódicos científicos e técnicos brasileiros. Ciência da Informação, 27(2), 165-175.

Menandro, P. R. M. (2001, outubro). Uma nova etapa na avaliação de periódicos científicos utilizados por pesquisadores brasileiros da área da Psicologia. Trabalho apresentado na XXXI Reunião Anual da Sociedade Brasileira de Psicologia, Rio de Janeiro, RJ.

Trzesniak, P. (2001). A concepção e a construção da revista científica. In I Curso de Editoração Científica (pp. 11-24). Brasília: CEDRHUS.

Yamamoto, O. H., Koller, S. H., Guedes, M. C., LoBianco, A. C., Hutz, C. S., Bueno, J. L. O., Macedo, L., \& Menandro, P. R. M. (1999). Periódicos científicos em Psicologia: uma proposta de avaliação. Infocapes, 6(3), 7-13.

\section{Notas}

1 Dados apresentados por Trzesniak (2001), a partir de uma comunicação de C. Zielinski, no VI Encon-

tro Nacional de Editores Científicos, em Caxambu (MG), novembro de 1996.

2 Para uma discussão, ver Gibbs (1995). 
3 Material sobre a avaliação pode ser encontrado em Yamamoto et al. (1999), na edição 5.2 da revista Estudos de Psicologia (disponível no SciELO, http://www.scielo.br/epsic), e no site da ANPEPP (http:// www.anpepp.org.br).

$4 \quad$ Haja vista a situação das universidades federais, o segmento responsável pela maior parte da produção científica no Brasil, abandonada à própria sorte, pelo descaso do Estado com relação à educação pública.

\section{Nominata dos conselheiros e consultores ad hoc}

\author{
Abigail Alvarenga Mahoney \\ Acácia Aparecida Angeli dos Santos \\ Albanise de Oliveira Lima \\ Alvaro Tamayo \\ Ana Beatriz Freire \\ Ana Maria de Toledo Piza Rudge \\ Ana Teresa de Abreu Ramos Cerqueira \\ Anna Carolina LoBianco \\ Antonia da Silva Solino \\ Antônio Cabral Neto \\ Antônio da Costa Ciampa \\ Antônio Gomes Penna \\ Antonio Roazzi \\ Arrilton Araújo de Souza \\ Carlos Eduardo Cameschi \\ Carmen Garcia de Almeida \\ Élida Sigelmann \\ Elisa Maria Parayba Campos Ribeiro \\ Elizabeth Joan Barham \\ Elza Maria do Socorro Dutra \\ Fúlvia Maria B. Rosemberg \\ Geraldo José de Paiva \\ Gilberto Safra \\ Grauben José Alves de Assis \\ Helerina Aparecida Novo \\ Heloisa Symanski Ribeiro Gomes \\ Herculano Ricardo Campos \\ Ingedore Villaça Koch \\ Iraí Cristina Boccato Alves \\ Isaura Rocha Figueiredo Guimarães \\ Isolda de Araújo Günther \\ Jane Correa \\ John Fontenelle de Araújo \\ Jorge La Rosa \\ José Carlos Zanelli \\ José Leon Crochik \\ José Tolentino Rosa \\ Junia de Vilhena
}

Leny Sato

Leoncio Rodriguez Larrain Camino

Lídio de Souza

Lúcia Rabello de Castro

Luís Flávio Silva Couto

MagdaDimenstein

Marco Antônio de Castro Figueiredo

Marcos Ribeiro Ferreira

Maria Amélia Mattos

Maria Aparecida Trevisan Zamberlan

Maria Clotilde Therezinha Rossetti Ferreira

Maria do Carmo Fernandes Martins

Maria do Carmo Guedes

Maria Emília Yamamoto

Maria Lúcia Boarini

Maria Lúcia Faria Moro

Maria Margarida Pereira Rodrigues

Maria Regina Maluf

MarildaEmmanuel Novaes Lipp

MarthaTraverso-Yepez

Paula Inez Cunha Gomide

Perter Kevin Spink

Raul Aragão Martins

Ronald João Jacques Arendt

Sadao Omote

Sandra Maria Mata Azerêdo

Sávio Silveira Queiroz

Sérgio Antonio da Silva Leite

Sérgio Ozella

Sílvia Helena Koller

Sílvia Regina Ricco Lucato Sigolo

Sonia Regina Fiorim Enumo

Sylvia Leser de Mello

Valdiney Velôso Gouveia

Verônica Bender Haydu

Yolanda Cintrão Forhieri

Zeidi Araújo Trindade

Zilda Aparecida Pereira del Prette 